Conspiracy Beliefs and Distrust of Science Predicts Reluctance of Vaccine Uptake of Politically

Right-Wing Citizens

Authors:

Winter, T. ${ }^{a}$, Riordan, B. C. ${ }^{b}$, Scarf, D. ${ }^{c}$, \& Jose, P. E. ${ }^{a}$

Affiliations:

a) Victoria University of Wellington, Wellington, New Zealand

b) La Trobe University, Melbourne, Victoria, Australia

c) University of Otago, Dunedin, Otago, New Zealand

Corresponding author:

Taylor Winter

School of Psychology

Victoria University of Wellington

PO Box 600

Wellington 6140

New Zealand

taylor.winter@vuw.ac.nz 


\begin{abstract}
It is not uncommon for conspiracy theories to have a political agenda, i.e., some conspiracies are more endorsed by the political left-wing than the political right-wing and vice-versa. Conspiracy theories quickly flourished as the COVID-19 pandemic emerged and this may have been an underlying factor in a reluctance by some in following public health policies such as the wearing of face masks. In the present study, we surveyed a community sample of 1358 adults just prior to the COVID-19 vaccine rollout in Aotearoa New Zealand. Our first aim was to determine whether one's political orientation, whether they are politically left- or right-wing, would be predictive of an individual's belief in conspiracy theories and determine whether this relationship can be exacerbated by a distrust in science. The second aim was to determine how such a relationship could explain an individual's vaccine hesitancy. Our results supported that indeed those that identify as right-wing tended to have hire hesitancy associated with taking the COVID-19 vaccine. However, we demonstrated that this association, in part, can be explained by a corresponding belief in COVID-19 related conspiracies. Interestingly, such a relationship only emerged in the presence of a general distrust in science. In other words, if a right-wing individual has at least a moderate trust in science, they demonstrated similarly low endorsement of COVID-19 conspiracies as their left-wing counterparts. Mitigating the right-wing endorsement of COVID-19 conspiracies then aligned with a reduction in vaccine hesitancy. Our findings indicated that public interventions seeking to increase trust in science may mitigate right-wing endorsement of conspiracy theories and thus lead to a more unified and positive response to public health behaviours such as vaccination.
\end{abstract}

Keywords: conspiracies, political orientation, distrust, science, vaccines 


\section{Conspiracy beliefs and distrust of science predicts reluctance of vaccine uptake of politically right- wing citizens}

Conspiracy theories, namely alternative and unsubstantiated explanations of events that contradict current rational or scientific thinking, have been prevalent throughout human history (van Prooijen \& Douglas, 2017). The COVID-19 pandemic has served to provide fertile ground for conspiracy theories to proliferate, even beyond the very small portion of the population in which conspiracies are usually contained. Freeman et al. (2020) have shown, specifically, that $50 \%$ of their 2,501 adult sample in the UK showed some level of COVID-19 conspiracy theory endorsement (e.g., 'The spread of the virus is a deliberate attempt by one nation to destabilize another') and $25 \%$ showed moderate to high levels of endorsement. Similarly, in a representative sample of 3,019 American adults, $49 \%$ of people believed COVID-19 to be a biological weapon developed by China (Miller, 2020). The staggering upturn in COVID-19 conspiracy theory support and resultant potential impact on behaviour and policy outcomes forms a critical point of investigation as countries attempt to manage COVID-19 and start implementing vaccine programmes.

Most conspiracies are quite cynical with a general theme of questioning institutional powers, such as implications of collusion by large pharma companies who are accused of hiding a cure for the COVID-19 virus to maximise profit (Bernard et al., 2020). However, during the current pandemic, more extreme narratives have found disproportionately wide acceptance. For example, the theory that $5 \mathrm{G}$ cell towers caused or worsened COVID-19 infection led to people burning down cell towers both in New Zealand and overseas (How 5 G and Covid-19 Mixed to Make a Toxic Conspiracy Cocktail, 2020; Jolley \& Paterson, 2020). In fact, 5G conspiracies were so prevalent and damaging to infrastructure that New Zealand's Ministry of Health released an extensive factsheet on 5G (Cellsites and 5G, 2021). It seems that the severity of the threat of the COVID-19 pandemic has fuelled belief in a wider variety of, and more extreme versions of, conspiracy theories. However, it is of greater concern that COVID-19 conspiracies have had a very real impact on population health, 
such as leading people to avoid testing, not comply with mask mandates, or not get vaccinated (Allington et al., 2020; Earnshaw et al., 2020; Freeman et al., 2020; Romer \& Jamieson, 2020).

In a political environment, conspiracy theories have been increasingly pertinent both as a tool for political gain ("Trump Has Called Climate Change a Chinese Hoax," 2016), and as a hindrance to policy implementation (“Water Wars," 2018). Where people typically align themselves on a scale ranging from the political left with liberal views, and the political right with conservative views, conspiracy theories have about equally manifested at both ends of this political spectrum. Conspiracy beliefs seem to typically arise and prosper at both the extreme left and right ends of the political spectrum (Sutton \& Douglas, 2020; van Prooijen et al., 2015). However, most of the research on COVID-19-linked conspiracy theories has noted (Miller, 2020; Uscinski et al., 2020) that politically conservative or right-wing citizens (e.g., Republicans in the U.S.) are more likely to report reluctance to adhere to public health recommendations because of belief in conspiracy theories. In particular, right-wing Americans are far less likely to support and follow COVID-19 community health policies such as wearing face masks (Miller, 2020). Interestingly, the partisan effects have been quite varied elsewhere, such as Canada that has shown cross-party support for COVID-19 policy and thus a non-partisan endorsement by constituents (Merkley et al., 2020).

In the present case, New Zealand appears to be somewhere between these two extremes with the right-of-centre National party being particularly outspoken about opening borders sooner, and arguing against the use of lockdowns (i.e., shelter in place orders ("New Zealand Businesses 'sacrificial Lambs' in COVID-19," 2020; “National Calls for Travel Bubble," 2021)). However in more recent months, there has been a shift towards greater alignment between National and the left-ofcentre Labour party ("No Alternative to Lockdown," 2020). In the broad sense, there is a need to better understand the associations among political affiliation, conspiracy theories, perceptions of COVID-19, and intention to engage in science-recommended public health behaviours. Unfortunately, the literature on political party differences in conspiracy beliefs is quite scant 
internationally, and even more so in New Zealand. In our search, we have not yet found a study examining the ability of political beliefs to predict subsequent COVID-19 conspiracy beliefs, and, in turn, the ability of conspiracy beliefs to predict COVID-19 policy adherence (e.g., does conspiracy beliefs statistically mediate the relationship between political beliefs and COVID-19 policy adherence). The existing research focuses on relationships between two variables at a time (Gollwitzer et al., 2020; Pummerer et al., 2021), not three, as we propose to do here.

A number of researchers (Brzezinski et al., 2020; Rutjens et al., 2021) have also noted that distrust of science and scepticism towards medical advice is an important factor to overcome in the control of COVID-19 and distribution of vaccines. The role of science distrust was pointed out in a German study (Post et al., 2021), drawing on a representative sample of 1,513 individuals, which indicated a distinct difference in people's informational requirements when making decisions on whether to endorse COVID-19 policy. Specifically, Post et al. (2021) identified two main groups of individuals, one group composed of people who intend to form their own opinions and sought information through traditional media, and another group who felt scientists could be trusted to independently provide oversight on policy. Clearly there is a need to take one's trust or distrust of science into consideration when determining a citizen's proclivity towards conspiracy theories and community health behaviour. Importantly, one's trust in science appears to be predicted by one's political orientation in that individuals who are more politically left-wing tend to report a higher belief in science, whereas the opposite is true of right-wing individuals (Costello et al., 2020).

In the present paper, we sought to examine the relationships between political beliefs, COVID19 conspiracy beliefs, distrust of science, and intention to receive a vaccination in a single model (whereas these relationships have previously been studied in pairs). We applied our understanding of these relationships to the timely and important behaviour of taking the COVID-19 vaccine. First, we sought to determine whether political beliefs predict conspiracy beliefs, and whether a person's distrust of science moderates the strength of this relationship. Second, we applied this moderation 
model to the outcome of vaccine uptake, i.e., determining whether political beliefs predict vaccine uptake and whether such an effect can be explained by one's strength of belief in COVID-19 conspiracies (i.e., mediation), then, third, whether the mediating effect would be moderated by a distrust in science. We predicted that those individuals who are politically conservative would be more likely to endorse COVID-19 conspiracies as suggested by overseas data and local news reports. We then predicted that as distrust of science increases, so too does inclination to believe COVID-19 conspiracies for those individuals who are conservative, but not liberal. Lastly, we predicted that although those individuals who are politically conservative would be less likely to take the COVID-19 vaccine, most of this effect can be explained by a corresponding belief in COVID-19 conspiracies, which in turn would be enhanced in the presence of a corresponding distrust of science.

\section{Methods}

\section{Participants and procedure}

The present study draws on a single wave from a longitudinal survey conducted in New Zealand using a community sample recruited using social media and press coverage of the study in mainstream media (see XXXX et al., 2020 for additional information). The variables of interest in the present study were only collected in the second timepoint, and thus we could not leverage a longitudinal design, however, we discuss the full survey collection procedure for transparency. The initial survey was conducted across two time-points during New Zealand's Alert Level 4 (highest level of lockdown used to combat community transmission) and Alert Level 1 (no restrictions) immediately after the lockdown was lifted. The follow-up survey was conducted approximately eight months later using participants who opted in during the initial survey. Of the 3601 who participated in the two initial survey waves, 2242 opted into follow-up, of which 1648 completed the follow-up survey (with the follow-up containing the variables used herein). While assessing the quality of the data, we noticed that 13 individuals conducted the survey multiple times from the same email invitation and these people were removed, and 303 individuals did not complete the question on 
political beliefs. Fortunately, we did ask political beliefs in the initial survey and, where political beliefs were missing from the second time point, we imputed the previous time point's political beliefs ( 255 of the 303 cases).

\section{Measures}

Demographics. Self-reported age and sex were gathered during the initial survey and joined onto the follow-up survey containing all other questions used in the present study.

Political beliefs. Participants were presented with a single item Likert scale ranging from 1 (conservative) to 7 (liberal) after being prompted with the question: "Often, people use the terms "conservative" or "liberal" to describe their political beliefs. How would you rate yourself in these terms?". Responses were standardised prior to analysis.

Distrust of science. Six questions were asked about one's belief in the credibility of science using a scale developed by Hartman et al (2017). Responses were Likert scales ranging from 1 (strongly disagree) to 7 (strongly agree). All questions were negatively worded (i.e., in the direction of science distrust) and the scale included items such as "People trust scientists a lot more than they should".

Conspiracy beliefs. A series of 20 questions tapping common COVID-19 related conspiracies were constructed for the purposes of the present study headed with the prompt "How confident are you that the following statements about COVID-19 are true or false?" Responses consisted of fivepoint Likert scales ranging from 1 (Confident is FALSE) to 5 (Confident is TRUE). Examples include "The government is misleading the public about the cause of COVID19" and "COVID19 is a hoax" (the full list of questions is presented in Appendix A). Three questions related specifically to vaccination, e.g., "COVID19 was created to force everyone to get vaccinated", and we removed these questions before analyses so as not to bias the relationship between one's general COVID-19 conspiracy beliefs and one's proclivity to obtain a vaccine. Exploratory Data Analysis (EDA) supported 
a single factor structure for conspiracy questions, and thus a single latent factor was constructed for analysis (See Appendix B for full results of EFA).

Vaccine uptake. We asked the question "Which of the following statements do you agree with the most?" and posed four options concerning intentions to take the vaccine. Participants were constrained to select a single option.

- Once a vaccine is developed, $l^{\prime} d$ be keen to try it even if the scientific community isn't certain about effectiveness and safety.

- I will wait until the scientific research confirms that the vaccine is effective and safe before taking it.

- I will wait until lots of other people take it without ill effect before, I'll take it.

- I will NOT take any vaccine for the coronavirus because I fear that it will not be safe.

Responses were binarized to yield two groups: 1) 'hesitant', i.e., those individuals who would not take the vaccine or would wait until lots of other people take it; and 2) 'compliant', i.e., those individuals who would take a vaccine with or without scientific certainty of safety and efficacy.

\section{Analytical strategy}

Confirmatory Factor Analysis (CFA) was used to generate latent variables for conspiracy beliefs and distrust of science. In the case of conspiracy beliefs, we utilised parcelling, whereby we averaged every fourth item together, forming four parcels (Hau \& Marsh, 2004). We then used Bayesian regression to first determine if there was an association between political beliefs and conspiracy beliefs, and second, whether the association was moderated by one's belief in science. The model specified conspiracy beliefs as the outcome predicted by political beliefs, science beliefs, age, and sex (latter two variables were covariates). An interaction between political beliefs and science beliefs was next entered to test for moderation (Figure 1a). In the follow-up analysis, we conducted a moderated mediation with the binary variable, vaccine uptake, as the outcome and 
political beliefs as the predictor. We entered conspiracy beliefs as a mediator and science beliefs as a moderator of the ' $a$ ' path, with age and sex entered as covariates of the moderator and outcome variables (Figure 1b). As shown in Figure $1 b$, the ' $a$ ' path is effectively the first analysis, with an additional direct path from political beliefs to vaccine uptake ('c prime') and the ' $b$ ' path from conspiracy theories to the outcome, all of which constitute a mediation analysis with vaccine uptake as the outcome.

Figure 1. Structural equation model for the two analyses.

a)

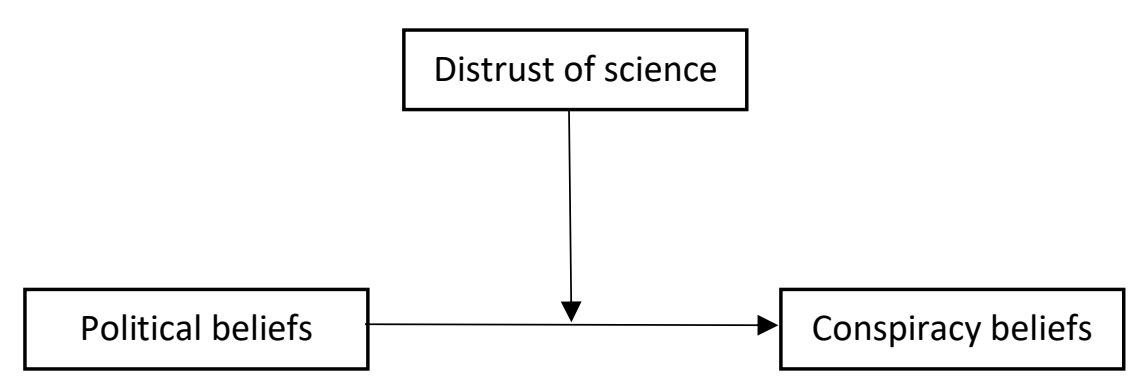

b)

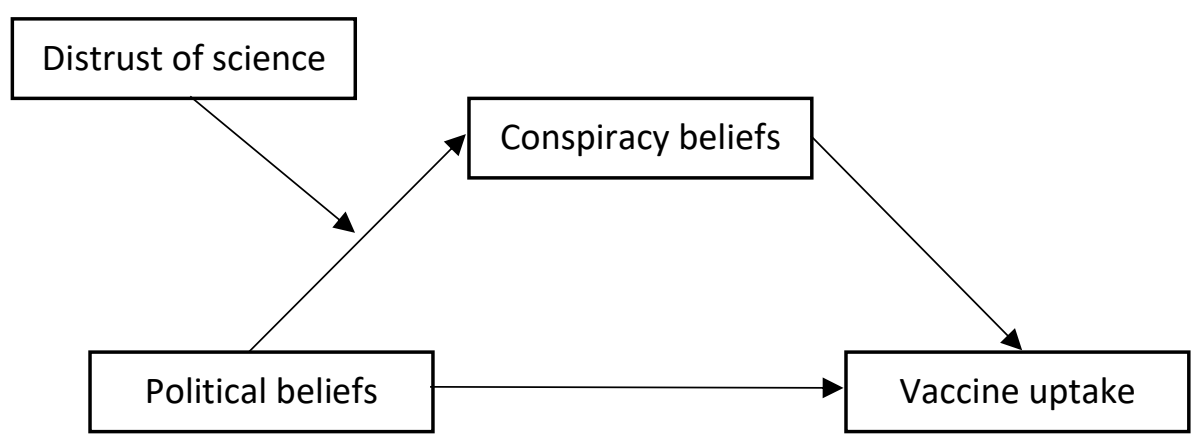

\section{Results}

The sample yielded a mean age of 51 years old $(S D=16)$ and $42 \%$ of the sample was male (Table 1). A good representation across the political spectrum was obtained with political beliefs averaging $4.7(S D=1.4)$ for a 7-point scale, and most people $(78 \%)$ were willing to take a COVID-19 vaccine. Importantly, the proportion of people not willing to take a vaccine was well within tested tolerances for sources of bias introduced when using binary responses in structural equation models (Huang et al., 2004; Samawi et al., 2018). All continuous variables manifested low levels of skewness 
except for conspiracy beliefs which yielded a positive skew (but still within traditional levels of tolerance ranging from -3 to 3 ).

CFA results demonstrated good fit of all items for distrust of science, with all items loading significantly $(p<0.01)$ and an acceptable Comparative Fit Index (CFI) of 0.93 was obtained. Conspiracy beliefs also demonstrated significance of each item loading into a single factor, after parcelling, all four parcels loaded significantly, and CFI was high (0.99). All regression models were evaluated and reached acceptable convergence based on Rhats (equal to or close to one, suggesting good convergence) and effective sample sizes (which all ranged in the thousands suggesting good coverage of the parameter space).

Table 1. Demographics and descriptive statistics of variables used in present analyses.

\begin{tabular}{lccccc}
\hline & Mean & SD & Min & Max & Skew \\
\hline Age & 50.87 & 16.00 & 17.00 & 16.02 & -0.15 \\
Sex (\%) & $42 \%$ [male] & & & & \\
Conspiracy beliefs & 0.00 & 0.38 & 1.74 & -0.34 & 1.94 \\
Distrust of science & 0.00 & 1.25 & 4.00 & -1.70 & 0.89 \\
Political beliefs & 4.69 & 7.00 & 1.00 & 1.41 & -0.37 \\
Willingness to take vaccine (\%) & $78 \%$ & & & & \\
\hline
\end{tabular}

\section{Relationship between political beliefs and conspiracy beliefs}

The Bayesian regression predicting conspiracy beliefs yielded an $R^{2}$ of 0.44 . The measure of political beliefs was a negative predictor of conspiracies, i.e., Liberal people did not endorse this set of conspiracy theories as strongly as conservative people (Table 2). Similarly, distrust of science increased with conspiracy beliefs, i.e., people reporting high distrust of science endorsed high levels of conspiracy theories. The analysis also identified a significant moderation effect, within the context of a general negative association between liberal political beliefs and conspiracy theories, people reporting high levels of distrust in science reported very high levels of belief in conspiracies when they reported a conservative political orientation, but not when they reported a liberal political orientation (see Figure 2). In sum, high levels of distrust in science exacerbated the general negative 
association between political orientation and conspiracy beliefs. Neither of the covariates, i.e., age and sex, had much effect on conspiracy beliefs with credible intervals of both covariates heavily overlapping the value of zero.

Figure 2. Marginal effect of political beliefs on conspiracy beliefs for different levels of scientific beliefs. Shaded areas represented $95 \%$ credible intervals.

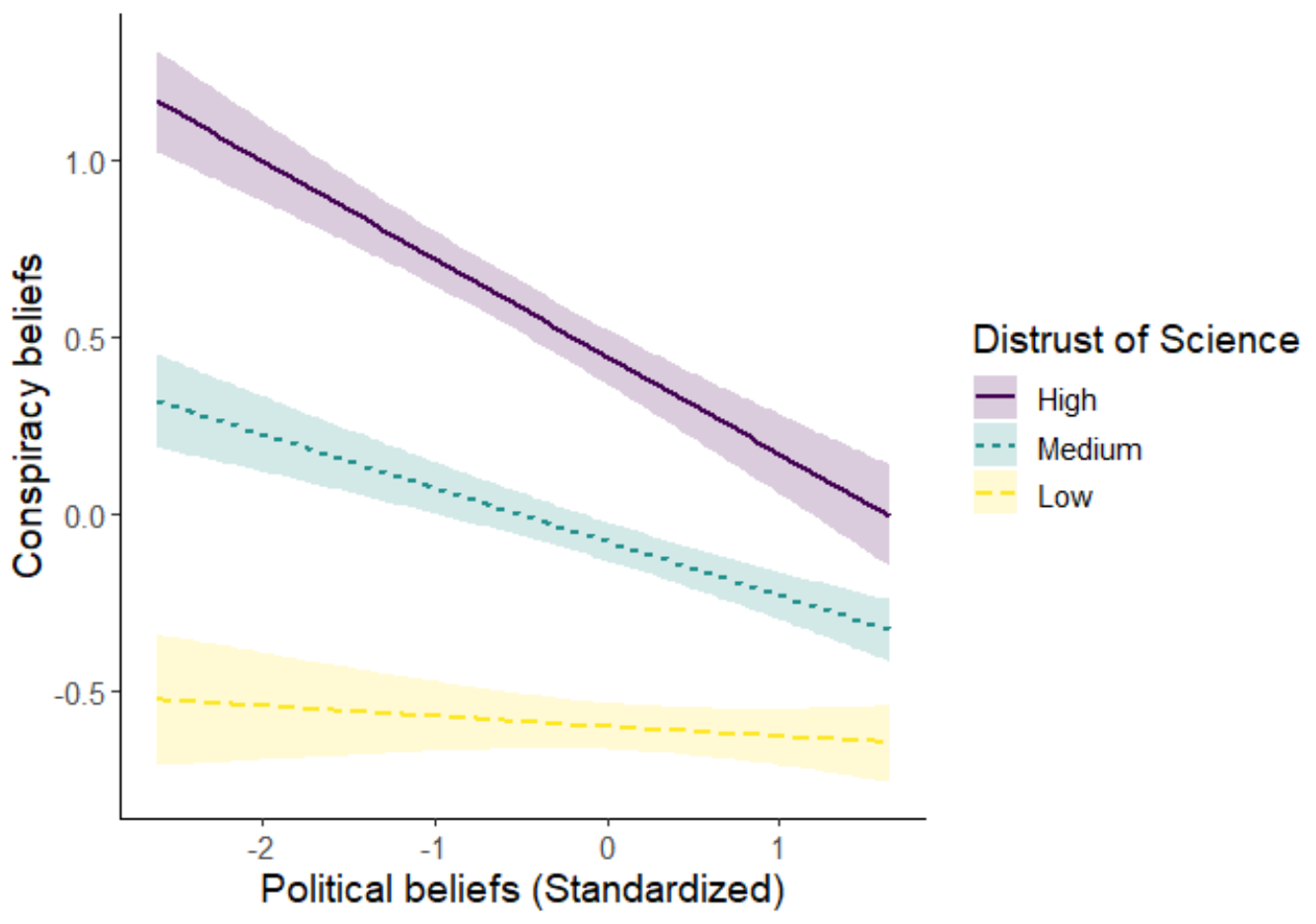

Distrust of science as a moderator of the mediation by conspiracy theories between political beliefs and vaccine uptake

The moderated mediation analysis yielded a significant ' $a$ path' in that political beliefs predicted conspiracy beliefs, and a significant ' $b$ path' in that conspiracy beliefs indicated a lower odd of taking a COVID-19 vaccine (see Table 2). Interestingly the ' $c$ ' path', or direct effect of political beliefs on vaccine uptake, had a small albeit significant effect. Specifically, there was a $96 \%$ chance that liberal people would report a higher probability of taking the vaccine relative to conservative people. Using the product of coefficients approach, i.e., multiplying posterior distributions of the ' $a$ and $b$ paths', we detected a significant indirect effect suggesting conspiracy beliefs mediated the 
effect between political beliefs and odds of vaccine uptake $\left(a^{*} b=0.13,95 \% \mathrm{Cl}=[0.09,0.19]\right)$. The mediation result suggests that politically conservative participants were likely to endorse higher numbers of conspiracy theories, which, in turn, predicted vaccine hesitancy. In addition, we also noted that the analysis yielded a significant interaction between political beliefs and distrust of science when predicting the ' $a$ path' linking political beliefs to conspiracy beliefs (see Figure 1a). This finding indicates a significant moderation of the ' $a$ path', which is a case of moderated mediation. We tested the direction and size of the indirect effect under three different levels of distrust of science beliefs to understand how the moderation affected the mediation model. For individuals who reported low levels of distrust of science $(-1)$, the indirect effect was very small $(a * b=0.02)$, which only explained $16 \%$ of the total effect (Table 3). At a medium (or mean) level of distrust of science (0), we observed a higher indirect effect $\left(a^{*} b=0.14\right)$, relative to low levels of distrust in science. For individuals reporting high levels of distrust of science (1), the estimate of the indirect effect increased to 0.25 , which explained $40 \%$ of the total effect in the model. Clearly, as distrust of science increased, the moderation increasingly strengthened the indirect effect. These results, taken together, suggest that conservative political orientation predicted higher levels of endorsement of conspiracy theories and subsequent vaccine hesitancy generally, and distrust of science exacerbated this mediation result.

Table 2. Regression results for the mediator and outcome in the moderated mediation analysis presenting median coefficients and $95 \%$ credible intervals.

\begin{tabular}{lccccc}
\cline { 2 - 3 } \cline { 5 - 6 } Predictors & \multicolumn{2}{c}{ Conspiracy beliefs } & & \multicolumn{2}{c}{ Vaccine uptake } \\
\hline Intercept & Estimates & $\mathrm{Cl}(95 \%)$ & & Ln(Odds) & $\mathrm{Cl}(95 \%)$ \\
Political beliefs & -0.07 & $-0.13,-0.02$ & & 3.15 & $2.65,3.78$ \\
Conspiracy beliefs & -0.15 & $-0.20,-0.11$ & & 1.15 & $0.99,1.35$ \\
Age & & & & 0.41 & $0.35,0.47$ \\
Sex [male] & 0.00 & $-0.04,0.04$ & & 1.00 & $0.86,1.16$ \\
Distrust of science & 0.03 & $-0.06,0.11$ & & 1.47 & $1.10,2.01$ \\
Political beliefs * Distrust of science & 0.51 & $0.46,0.55$ & & & \\
\cline { 1 - 2 } & -0.13 & $-0.16,-0.09$ & & \\
\hline
\end{tabular}


Table 3. Mediation results for different levels of scientific beliefs as an a-path moderator presenting median effects and $95 \%$ credible intervals. Note that multiplication of negative a- and b-paths leads to the $95 \% \mathrm{Cls}$ being reversed on subsequent derived effects.

\begin{tabular}{|c|c|c|c|c|c|c|}
\hline \multirow[b]{2}{*}{ Effect } & \multicolumn{2}{|c|}{ High distrust of science } & \multicolumn{2}{|c|}{$\begin{array}{l}\text { Moderate distrust of } \\
\text { science }\end{array}$} & \multicolumn{2}{|c|}{ Low distrust of science } \\
\hline & Estimate & $\mathrm{Cl}(95 \%)$ & Estimate & $\mathrm{Cl}(95 \%)$ & Estimate & $\mathrm{Cl}(95 \%)$ \\
\hline a - path & -0.28 & $-0.37,-0.20$ & -0.15 & $-0.20,-0.10$ & -0.02 & $-0.03,-0.01$ \\
\hline b - path & -0.90 & $-1.05,-0.75$ & -0.90 & $-1.05,-0.75$ & -0.90 & $-1.05,-0.75$ \\
\hline Direct effect ( $\left.c^{\prime}\right)$ & 0.14 & $-0.01,0.30$ & 0.14 & $-0.01,0.30$ & 0.14 & $-0.01,0.30$ \\
\hline Indirect effect & 0.25 & $0.39,0.15$ & 0.14 & $0.21,0.08$ & 0.02 & $0.03,0.01$ \\
\hline Total effect & 0.64 & $1.03,0.33$ & 0.49 & $1.05,0.21$ & 0.13 & $1.40,0.03$ \\
\hline Proportion mediated & 0.40 & $0.38,0.44$ & 0.28 & $0.20,0.37$ & 0.16 & $0.02,0.31$ \\
\hline
\end{tabular}

Sample size

$\mathrm{N}=1358$

\section{Discussion}

Data obtained in the present study supported our primary hypothesis that politically conservative individuals were more likely to endorse COVID-19 based conspiracy theories than politically liberal individuals. We also obtained support for our hypothesis that distrust in science can intensify belief in conspiracies, and this moderation effect was prominent for conservatives, but not for liberals. In particular, when individuals reported low distrust in science, both liberals and conservatives manifested a similarly low support of COVID-19 conspiracies. However, when an individual reported a high distrust in science, conservative individuals were far more likely to endorse COVID-19 conspiracies than their liberal counterparts. Lastly, we supported the hypothesis that those individuals holding conservative beliefs were more likely to demonstrate reluctance to take the COVID-19 vaccine although the direct relationship was small. The reluctance of vaccine uptake by conservatives appeared to be largely explained by a concurrent belief in COVID-19 conspiracies, an effect exacerbated by a distrust in science.

Our findings showed that conservative voters, particularly those who distrust science, were likely to hold conspiracy beliefs, and these beliefs significantly predicted vaccine hesitancy. However, the fact that only conservatives were so strongly influenced by distrust of science lends itself to more bespoke points of intervention to ensure wider public support of public health initiatives. If 
conservative politicians more strongly endorse scientific advice then this type of leadership could reduce the influence of conspiracy beliefs by persuading more individuals to adopt medium or low levels of the moderator, i.e., generally decrease distrust in science. We would further note that without a distrust of science, conservative individuals showed comparably low levels of conspiracy beliefs in COVID-19, further supporting the view that distrust of science may be a more fruitful point of intervention and not conservativism more generally. Indeed, scientific endorsement by the political right in Canada may explain the largely bipartisan support of health policies through the pandemic (Merkley et al., 2020).

\section{Limitations and Future Directions}

Despite the large sample size, the present study was not without its limitations. In particular, our findings should be examined with longitudinal analyses. This approach was not possible within the current survey design as all required data were not gathered at multiple time points. For example, it may be that a temporal examination of these relationships would show that belief in conspiracy theories leads to and predicts greater distrust in science rather than the reverse. Similarly, we would be able to observe how the changing COVID-19 environment could change the observed relationships, e.g., with emerging stories of blood clots temporally associated with vaccination.

We also need to test whether likely malleable variables yield the expected outcomes. For example, an experimental approach could be utilised to determine whether a conservative leader can reduce an individual's beliefs in conspiracies (and thereby reduce vaccine hesitancy) by endorsing a trust in science. Future work would do well to tackle the nature of relationships among political conservatism, science distrust, and belief in conspiracies -in some people these linkages seem strong and impervious to change whereas for other people, the network of beliefs may be more amenable to change. 
Our findings also have implications for health policies around the world. In our sample, $22 \%$ of individuals wanted to wait until most other people had taken the vaccine or would not take the vaccine at all due to health concerns. This statistic, already quite high, can easily increase dangerously should science-based activities, and specifically the roll-out of vaccines, be shown to be flawed. Such a concern is not exaggerated given the publicity about deaths reputedly caused by rare blood clots that are yet to be dissociated from the vaccine (COVID-19 Vaccines and Rare Cases of Blood Clots with Bleeding: No Current Risk with Comirnarty (Pfizer/BioNTech) Vaccine, n.d.). Similarly batches of vaccine were destroyed and further import was banned in Brazil when the Russiansupplied vaccine was allegedly contaminated with live influenza virus (Cold Virus Lurking in Russian Sputnik Vaccine, Says Brazil, 2021; Sputnik V Backers Sue Brazilian Health Watchdog over Criticism of Russian Jab, n.d.). Public trust can be weakened by awkward scientific communication or intentionally malicious political activity, so governments and political actors need to be aware of the consequences (Kreps \& Kriner, 2020).

\section{Conclusions}

In sum, our study illuminated how a network of related belief-based constructs jointly predicted vaccine hesitancy. We have highlighted that, in New Zealand, conservatives manifested a lower likelihood of taking the COVID-19 vaccine relative to liberals, and in part, this relationship could be explained by a tendency for conservatives to also believe in COVID-19 conspiracies. The critical relationship we identified, however, was that the identified relationship between conservatives, conspiracies, and poor vaccine uptake only occurred in the presence of a distrust in science. These results may go some way to explaining why some countries experienced better bipartisan support of COVID-19 policies than other countries. We encourage future research to consider longitudinal examinations of the identified relationships and to test likely interventions that could improve support of public health policies. 


\section{References}

Allington, D., Duffy, B., Wessely, S., Dhavan, N., \& Rubin, J. (2020). Health-protective behaviour, social media usage and conspiracy belief during the COVID-19 public health emergency. Psychological Medicine, 1-7. https://doi.org/10.1017/S003329172000224X

Ardern accused of making New Zealand businesses "sacrificial lambs" in Covid-19 lockdown. (2020, April 21). The Guardian. http://www.theguardian.com/world/2020/apr/21/ardern-accusedof-making-new-zealand-businesses-sacrificial-lambs-in-covid-19-lockdown

Bernard, F. O., Akaito, J. A., Joseph, I., \& David, K. B. (2020). COVID-19: The trends of conspiracy theories vs facts. The Pan African Medical Journal, 35(Suppl 2). https://doi.org/10.11604/pamj.supp.2020.35.147.25536

Brzezinski, A., Kecht, V., Van Dijcke, D., \& Wright, A. L. (2020). Belief in Science Influences Physical Distancing in Response to COVID-19 Lockdown Policies. https://doi.org/10.2139/ssrn.3587990

Cellsites and 5G. (2021, March 12). Ministry of Health NZ. https://www.health.govt.nz/yourhealth/healthy-living/environmental-health/radiation-environment/cellsites-and-5g

Cold virus lurking in Russian Sputnik vaccine, says Brazil. (2021, April 29). The Independent. https://www.independent.co.uk/news/world/americas/sputnik-vaccine-russia-brazil-coldvirus-b1839559.html

Coronavirus: No alternative to Covid-19 lockdown strategy, says Health Minister Chris Hipkins. (2020, August 15). Stuff. https://www.stuff.co.nz/national/health/coronavirus/300083432/coronavirus-noalternative-to-covid19-lockdown-strategy-says-health-minister-chris-hipkins

Costello, T. H., Bowes, S., Stevens, S. T., Waldman, I., Tasimi, A., \& Lilienfeld, S. O. (2020). Clarifying the Structure and Nature of Left-Wing Authoritarianism. https://doi.org/10.31234/osf.io/3nprq 
COVID-19 vaccines and rare cases of blood clots with bleeding: No current risk with Comirnarty (Pfizer/BioNTech) vaccine. (n.d.). Retrieved May 20, 2021, from https://www.medsafe.govt.nz/safety/Alerts/COVID-19-vaccine-blood-clots.asp

Earnshaw, V. A., Eaton, L. A., Kalichman, S. C., Brousseau, N. M., Hill, E. C., \& Fox, A. B. (2020). COVID-19 conspiracy beliefs, health behaviors, and policy support. Translational Behavioral Medicine, 10(4), 850-856. https://doi.org/10.1093/tbm/ibaa090

Freeman, D., Waite, F., Rosebrock, L., Petit, A., Causier, C., East, A., Jenner, L., Teale, A.-L., Carr, L., Mulhall, S., Bold, E., \& Lambe, S. (2020). Coronavirus conspiracy beliefs, mistrust, and compliance with government guidelines in England. Psychological Medicine, 1-13. https://doi.org/10.1017/S0033291720001890

Gollwitzer, A., Martel, C., Brady, W. J., Pärnamets, P., Freedman, I. G., Knowles, E. D., \& Van Bavel, J. J. (2020). Partisan differences in physical distancing are linked to health outcomes during the COVID-19 pandemic. Nature Human Behaviour, 4(11), 1186-1197. https://doi.org/10.1038/s41562-020-00977-7

Hau, K.-T., \& Marsh, H. W. (2004). The use of item parcels in structural equation modelling: Nonnormal data and small sample sizes. British Journal of Mathematical and Statistical Psychology, 57(2), 327-351. https://doi.org/10.1111/j.2044-8317.2004.tb00142.x How 5 G and Covid-19 mixed to make a toxic conspiracy cocktail. (2020, May 19). RNZ. https://www.rnz.co.nz/news/on-the-inside/416991/how-5g-and-covid-19-mixed-to-make-atoxic-conspiracy-cocktail

Huang, B., Sivaganesan, S., Succop, P., \& Goodman, E. (2004). Statistical assessment of mediational effects for logistic mediational models. Statistics in Medicine, 23(17), 2713-2728. https://doi.org/10.1002/sim.1847

Jolley, D., \& Paterson, J. L. (2020). Pylons ablaze: Examining the role of 5G COVID-19 conspiracy beliefs and support for violence. British Journal of Social Psychology, 59(3), 628-640. https://doi.org/10.1111/bjso.12394 
Kreps, S. E., \& Kriner, D. L. (2020). Model uncertainty, political contestation, and public trust in science: Evidence from the COVID-19 pandemic / Science Advances. 6(43). https://doi.org/10.1126/sciadv.abd4563

Merkley, E., Bridgman, A., Loewen, P. J., Owen, T., Ruths, D., \& Zhilin, O. (2020). A Rare Moment of Cross-Partisan Consensus: Elite and Public Response to the COVID-19 Pandemic in Canada. Canadian Journal of Political Science/Revue Canadienne de Science Politique, 53(2), 311-318. https://doi.org/10.1017/\$0008423920000311

Miller, J. M. (2020). Psychological, Political, and Situational Factors Combine to Boost COVID-19 Conspiracy Theory Beliefs. Canadian Journal of Political Science/Revue Canadienne de Science Politique, 53(2), 327-334. https://doi.org/10.1017/S000842392000058X

National Party leader Judith Collins calls for immediate Pacific travel bubble. (2021, April 7). RNZ. https://www.rnz.co.nz/news/national/439950/national-party-leader-judith-collins-calls-forimmediate-pacific-travel-bubble

Post, S., Bienzeisler, N., \& Lohöfener, M. (2021). A desire for authoritative science? How citizens' informational needs and epistemic beliefs shaped their views of science, news, and policymaking in the COVID-19 pandemic. Public Understanding of Science, 09636625211005334. https://doi.org/10.1177/09636625211005334

Pummerer, L., Böhm, R., Lilleholt, L., Winter, K., Zettler, I., \& Sassenberg, K. (2021). Conspiracy Theories and Their Societal Effects During the COVID-19 Pandemic. Social Psychological and Personality Science, 19485506211000216. https://doi.org/10.1177/19485506211000217

Romer, D., \& Jamieson, K. H. (2020). Conspiracy theories as barriers to controlling the spread of COVID-19 in the U.S. Social Science \& Medicine, 263, 113356.

https://doi.org/10.1016/j.socscimed.2020.113356

Rutjens, B. T., van der Linden, S., \& van der Lee, R. (2021). Science skepticism in times of COVID-19. Group Processes \& Intergroup Relations, 24(2), 276-283.

https://doi.org/10.1177/1368430220981415 
Samawi, H., Cai, J., Linder, D. F., Rochani, H., \& Yin, J. (2018). A simpler approach for mediation analysis for dichotomous mediators in logistic regression. Journal of Statistical Computation and Simulation, 88(6), 1211-1227. https://doi.org/10.1080/00949655.2018.1426762

Sputnik V backers sue Brazilian health watchdog over criticism of Russian jab. (n.d.). Fortune. Retrieved May 20, 2021, from https://fortune.com/2021/04/30/sputnik-v-backers-suebrazilian-health-watchdog-over-criticism-of-russian-jab/

Sutton, R. M., \& Douglas, K. M. (2020). Conspiracy theories and the conspiracy mindset: Implications for political ideology. Current Opinion in Behavioral Sciences, 34, 118-122. https://doi.org/10.1016/j.cobeha.2020.02.015

Trump Has Called Climate Change a Chinese Hoax. Beijing Says It Is Anything But. (2016, November 18). NY Times. https://www.nytimes.com/2016/11/19/world/asia/china-trump-climatechange.html

Uscinski, J. E., Enders, A. M., Klofstad, C., Seelig, M., Funchion, J., Everett, C., Wuchty, S., Premaratne, K., \& Murthi, M. (2020). Why do people believe COVID-19 conspiracy theories? Harvard Kennedy School Misinformation Review, 1(3). https://doi.org/10.37016/mr-2020-015 van Prooijen, J.-W., \& Douglas, K. M. (2017). Conspiracy theories as part of history: The role of societal crisis situations. Memory Studies, 10(3), 323-333. https://doi.org/10.1177/1750698017701615 van Prooijen, J.-W., Krouwel, A. P. M., \& Pollet, T. V. (2015). Political Extremism Predicts Belief in Conspiracy Theories. Social Psychological and Personality Science, 6(5), 570-578. https://doi.org/10.1177/1948550614567356

Water wars: The 'cult-like' efforts to get fluoride out of America's drinking supply. (2018, October 18). NBC News. https://www.nbcnews.com/news/us-news/science-says-fluoride-watergood-kids-so-why-are-these-n920851 


\section{Appendix A}

Questions forming the belief in COVID-19 conspiracies scale

\section{How confident are you that the following statements about COVID-19 are TRUE or FALSE ?}

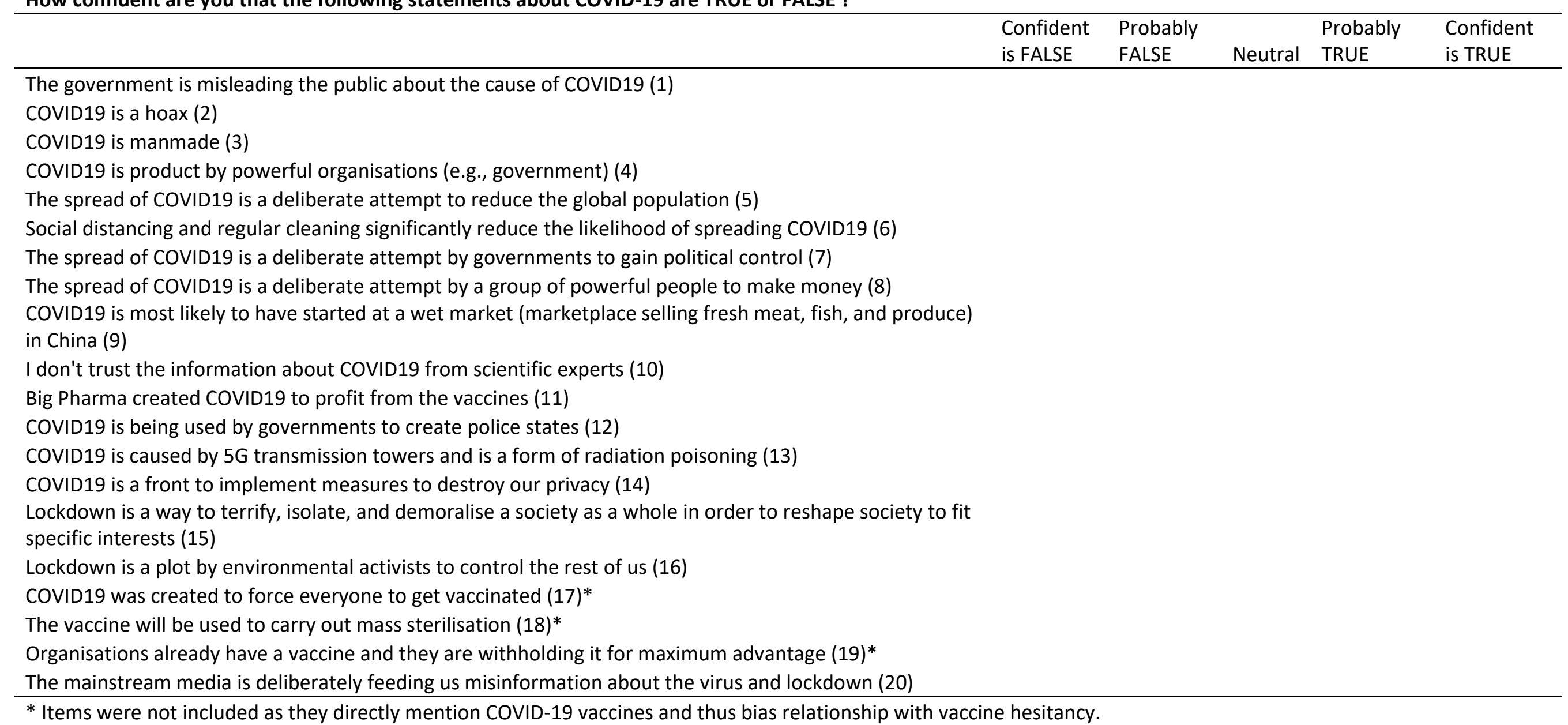




\section{Appendix B}

Table S1. Results of exploratory factor analysis leading all items onto a single factor for COVID-19 conspiracy beliefs.

\begin{tabular}{|c|c|c|c|c|}
\hline Item & Estimate & $\begin{array}{l}\text { Standard } \\
\text { error }\end{array}$ & z-value & p-value \\
\hline The government is misleading the public about the cause of COVID19 (1) & 1 & & & \\
\hline COVID19 is a hoax (2) & 0.51 & 0.02 & 22.00 & $<0.001$ \\
\hline COVID19 is manmade (3) & 1.02 & 0.04 & 24.49 & $<0.001$ \\
\hline COVID19 is product by powerful organisations (e.g., government) (4) & 0.96 & 0.04 & 27.11 & $<0.001$ \\
\hline The spread of COVID19 is a deliberate attempt to reduce the global population (5) & 0.70 & 0.03 & 25.92 & $<0.001$ \\
\hline Social distancing and regular cleaning significantly reduce the likelihood of spreading COVID19 (6) & -0.47 & 0.03 & -19.29 & $<0.001$ \\
\hline The spread of COVID19 is a deliberate attempt by governments to gain political control (7) & 0.97 & 0.03 & 29.55 & $<0.001$ \\
\hline The spread of COVID19 is a deliberate attempt by a group of powerful people to make money (8) & 0.92 & 0.03 & 29.04 & $<0.001$ \\
\hline COVID19 is most likely to have started at a wet market (marketplace selling fresh meat, fish, and produce) in China (9) & -0.54 & 0.03 & -16.38 & $<0.001$ \\
\hline I don't trust the information about COVID19 from scientific experts (10) & 0.94 & 0.04 & 23.85 & $<0.001$ \\
\hline Big Pharma created COVID19 to profit from the vaccines (11) & 0.64 & 0.03 & 26.05 & $<0.001$ \\
\hline COVID19 is being used by governments to create police states (12) & 1.06 & 0.04 & 26.49 & $<0.001$ \\
\hline COVID19 is caused by $5 \mathrm{G}$ transmission towers and is a form of radiation poisoning (13) & 0.19 & 0.01 & 16.10 & $<0.001$ \\
\hline COVID19 is a front to implement measures to destroy our privacy (14) & 0.92 & 0.03 & 29.29 & $<0.001$ \\
\hline \multicolumn{4}{|l|}{ Lockdown is a way to terrify, isolate, and demoralise a society as a whole in order to reshape society to fit specific } & $<0.001$ \\
\hline Lockdown is a plot by environmental activists to control the rest of us (16) & 0.71 & 0.03 & 27.46 & $<0.001$ \\
\hline \multicolumn{5}{|l|}{ COVID19 was created to force everyone to get vaccinated $(17)^{*}$} \\
\hline \multicolumn{5}{|l|}{ The vaccine will be used to carry out mass sterilisation $(18)^{*}$} \\
\hline \multicolumn{5}{|l|}{ Organisations already have a vaccine and they are withholding it for maximum advantage (19)* } \\
\hline The mainstream media is deliberately feeding us misinformation about the virus and lockdown (20) & 1.11 & 0.04 & 25.30 & $<0.001$ \\
\hline
\end{tabular}

* Items were not included as they directly mention COVID-19 vaccines and thus bias relationship with vaccine hesitancy. 